\title{
Fetal cardiac evaluation in HIV-positive women under HAART therapy in a Romanian hospital
}

\author{
ALEXANDRA URSACHE ${ }^{1}$, ALEXANDRA MARIA TIBEICA $^{2}$, ALEXANDRU LUCA $^{2}$, \\ MIRCEA ONOFRIESCU ${ }^{1,2}$, DANIELA ROXANA MATASARIU ${ }^{1}$ and DRAGOS NEMESCU ${ }^{1,2}$ \\ ${ }^{1}$ Department of Obstetrics and Gynecology, 'Grigore T. Popa' University of Medicine and Pharmacy, 700115 Iasi; \\ ${ }^{2}$ Department of Obstetrics ‘Cuza Voda' Obstetrics and Gynecology Clinical Hospital, 700038 Iasi, Romania
}

Received December 4, 2020; Accepted January 5, 2021

DOI: $10.3892 / \mathrm{etm} .2021 .10038$

\begin{abstract}
Human immunodeficiency virus (HIV) is an RNA (ribonucleic acid) virus that causes acquired immunodeficiency syndrome (AIDS). This disease has a major socioeconomical impact. The aim of the present study was to assess the fetal heart structure and function in HIV-positive pregnant women on highly active antiretroviral therapy (HAART). This is a prospective study conducted between January, 2018 and December, 2019. The hearts of fetuses from 14 HIV-positive pregnant women on HAART were assessed. Statistically significant sex-related cardiac changes in HIV-exposed uninfected fetuses of pregnant women on HAART were found. A narrow aorta was detected in female fetuses and a smaller left ventricular transverse diameter in male fetuses. Overall, the myocardial performance index remained unaltered. The impact of antiretroviral therapy on fetal heart seems to be sex-related. Accurate and complete information about the risks and benefits of antiretroviral treatment and management strategies to improve fetal outcomes may also ensure better compliance of the mothers to this treatment.
\end{abstract}

\section{Introduction}

Human immunodeficiency virus (HIV) was discovered in 1983 and is an ribonucleic acid (RNA) virus belonging

Correspondence to: Dr Daniela Roxana Matasariu, Department of Obstetrics and Gynecology, 'Grigore T. Popa' University of Medicine and Pharmacy, University Street 16, 700115 Iasi, Romania E-mail: roxanamatasariu@yahoo.com

Abbreviations: HIV, human immunodeficiency virus; RNA, ribonucleic acid; AIDS, Acquired Immunodeficiency Syndrome; HAART, Highly Active Antiretroviral Therapy; HEU, HIV-exposed uninfected fetuses; LV, left ventricular; ART, antiretroviral therapy; WHO, World Health Organization; DNA, deoxyribonucleic acid; PHACS, Pediatric HIV/AIDS Multicenter Cohort Study; MPI, myocardial performance index; MoM, multiple of the median; ROC curve, receiver operating characteristic curve

Key words: HIV, AIDS, pregnancy, antiretroviral therapy, fetal heart to the family Retroviridae that causes acquired immunodeficiency syndrome (AIDS). This virus targets the immune system T-helper cells, specifically $\mathrm{CD} 4^{+} \mathrm{T}$ cells, macrophages, and dendritic cells. Spreading extremely rapidly, it promptly achieved the characteristics of a pandemic. It has a significant socio-economic impact and represents a burden for the patient who must cope with the disease, lifelong treatment and social stigma (1-3).

HIV has become a manageable chronic condition since the introduction and development of antiretroviral therapy (ART) and 2013 World Health Organization (WHO) recommendation of lifelong treatment regardless of CD4 count and viral load (4-8).

While the benefits of ART are undebatable, there are concerns, especially about fetal side effects. Only a few studies were aimed at detecting the side effects of ART in HIV-exposed uninfected (HEU) children from HIV-positive mothers, but the results are conflicting. Thus, assessing the side effects of antiretroviral agents in fetuses and improving these children's outcomes is extremely important owing to highly active antiretroviral therapy (HAART's) impact on vertical transmission and maternal mortality and morbidity.

HIV disease is one of the leading causes of dilated cardiomyopathy with increasing prevalence as these patients experience a longer lifespan with the help of HAART therapy (9-11).

PHACS, a pediatric HIV/AIDS multicenter cohort study, showed that cardiac structure and function were better in HIV-positive children on HAART than in children not exposed to any ART. The prevalence of dilated cardiomyopathy decreased with access to antiviral treatment; however, exposure to antiretroviral drugs may increase the risk for coronary artery disease $(11,12)$.

This study aims to assess fetal heart function in HIV-positive pregnant women on HAART. The antiretroviral agents used during pregnancy were a combination of Kaletra and Combivir, with only one case being on Combivir and Isentress. Kaletra contains Lopinavir a protease inhibitor and Ritonavir as a booster, both of them inhibiting cytochrome P450, family 3, subfamily A (CYP3A4) isoenzyme. Combivir is a combination of two nucleoside/nucleotide reverse-transcriptase inhibitors, and Isentress is an integrase inhibitor $(13,14)$. 


\section{Materials and methods}

Patients. This prospective study was conducted between January, 2018 and December, 2019 at the University Hospital of obstetrics and gynecology 'Cuza-Voda', Iasi, Romania. The study was approved by the Ethics Committee of the Iasi 'Grigore T. Popa' University of Medicine and written consent was obtained from all the participants.

We included 14 HIV-positive women. The HIV-positive women had singleton pregnancies. They were on HAART, with complete obstetrical assessment during pregnancy and infectious disease evaluations. Cases with multiple pregnancies, incomplete obstetrical, or infectious disease assessments were excluded.

Methods. Fetal heart evaluation was performed using Voluson E8 ultrasound machine, with RAB 4-8D and RAB-6D probes. All measurements were performed by the same specialist in fetal cardiac assessment, to avoid interobserver variation. Fetal heart was assessed during the second-trimester morphological scan, mainly at 20 to 24 weeks of gestation. A later evaluation of the fetal heart function was carried out between 27 and 31 weeks of gestation. After the structural evaluation of the heart, we assessed its functional parameters and the myocardial performance index (MPI).

MPI was measured only in the left ventricle because previous studies showed that this parameter reflects the global cardiac function better. This index is independent of heart rate and cardiac chamber size (13-15).

Fetal heart was assessed by measuring the diameters of the aortic artery, pulmonary artery, aortic arch, ductus arteriosus, left and right atrial transverse diameters, and right and left ventricular transverse diameters, and the length of both ventricles. In addition, we evaluated the blood flow in the tricuspid, mitral, pulmonary and aortic valves.

Statistical analysis. Statistical analysis was performed using SPSS 25.0 software (SPSS Inc.). The continuous variables were evaluated to determine whether they had a gaussian distribution. The differences between the two group parameters, between 17 and 24 weeks of gestation and 25-31, were analysed using the one-way ANOVA with Bonferroni as the post-hoc test to determine any statistically significant differences. The only case that was evaluated a second time at 33 weeks of gestation was excluded. For all the evaluated parameters, the multiples of the median (MoM) and Z scores were calculated and then compared.

Afterwards, we analysed with normal range only the heart parameters that were not found as having a statistically significant difference between the two groups. We compared them, then we calculated the $\mathrm{Z}$ scores and MoM for each of them, with the normal range of parameters for fetal heart evaluation being investigated as previously indicated (15-17). The Student's t-test was to analyze the differences between the parameters of fetal hearts.

\section{Results}

Patients. We assessed the fetal hearts of 14 HIV-positive pregnant women, on HAART prior to conception. The study group had a mean age of 27.69 years, with a range between 24 and 30 years. Most of these women, 13 from 14 cases, were long-term survivors, being infected in early childhood during hospitalization for various diseases. Only one case had sexually transmitted HIV infection. All 14 pregnant women were under protease inhibitor treatment contained in HAART association prior to conception.

Of the 14 HIV-positive pregnant women with fetal cardiac evaluation, 12 had reached viral suppression prior to pregnancy. Thus, theoretically, the effect of the virus on fetal cardiac function was absent in these 12 cases. The two remaining cases had higher viral loads of 6,060 and 10,700 copies/ml. Two of the patients had coinfection with hepatitis $\mathrm{B}$ virus and one with hepatitis $\mathrm{C}$ virus.

Ten of the patients gave birth between 37 and 39 weeks of gestation, of which 7 had a planned C-section without being in labour. Four had premature birth, two at 35 weeks of gestation and 2 at 36 weeks. From the 14 fetuses 8 were females and 4 were males. The birth weight of the fetuses was between 1980 and 3,200 g. The male fetuses had a mean birthweight of $2,725 \mathrm{~g}$ and the female fetuses of 3,078 $\mathrm{g}$.

Fetal cardiac evaluation of HIV-positive pregnant women under HAART therapy. The evaluation of the fetal heart was performed mainly during the second trimester: 6 fetal heart evaluations of 17-24 weeks of gestation, and 11 fetal heart evaluations of 25-31 weeks of gestation. Not all the patients had both fetal heart evaluations because of the reduced addressability due to fear of social stigma. Only one case was assessed the second time correctly at 33 weeks of gestation but due to fetal position, the values were excluded from the analysis. The results of the fetal heart measurements between the two groups, 17-24 and 25-31 weeks of gestation, are shown in Table I. We assessed MoM values and Z-score for each parameter. We only used Z-scores at the end because it excludes gestational age as a variable. All the parameters that had statistically significant Z-score differences were excluded from further analysis. The cardiac function of 11 fetuses borne by the end of 2019, 7 females and 4 males were compared to determine whether there were any sex-related differences.

Excluded parameters from the statistical analysis. The size of the aorta had statistically significant differences between the two groups with Z-scores of: $-0.17( \pm 0.09)$ at 17-24 weeks, $-0.77( \pm 0.36)$ at $25-31$ weeks, with $\mathrm{P}=0.006$. The aortic arch of fetuses also had statistically significant Z-scores: $0.49( \pm 0.15)$ at $17-24$ weeks and $0.78( \pm 0.42)$ at $25-31$ weeks, with $\mathrm{P}=0.050$ (Table I).

The left atrium was statistically significantly larger in HEU fetuses (uninfected fetuses exposed to antiretroviral drugs) at 17-24 weeks of gestation with a $\mathrm{Z}$-score of $0.38( \pm 0.53)$ at $17-24$ weeks, $0.22( \pm 1.40)$ at $25-31$ weeks, $\mathrm{P}=0.046$. The ventricles had statistically significant $\mathrm{Z}$-score differences. The left ventricle transverse diameter had a Z-score of -0.96 $( \pm 0.13)$ at 17-24 weeks-0.98 ( \pm 0.91$)$ at 25-31 weeks, $\mathrm{P}=0.048$, but its length had no statistically significant variation. The right ventricle had both dimensions with statistically significant variation between groups: The transverse diameter: $-0.41( \pm 0.86)$ at $17-24$ weeks, $-1.07( \pm 1.46)$ at $25-31$ weeks, $\mathrm{P}=0.041$, and its length: $-0.58( \pm 1.21)$ at 17-24 weeks, $-1.09( \pm 1.00)$ at $25-31$ weeks, $\mathrm{P}=0.045$ (Table I). 
Table I. Fetal cardiac evaluation of HIV-positive pregnant women under HAART therapy-differences between the two different gestational age groups.

\section{Groups}

17-24 weeks (6 evaluations) 25-31 weeks (11 evaluations) One-way ANOVA test P-value

Tricuspid valve

$\operatorname{TrE} / \operatorname{Tr} \mathrm{A}( \pm \mathrm{SD})$

Z score $\operatorname{TrE} / \operatorname{Tr} \mathrm{A}$

Mitral valve

$\mathrm{ME} / \mathrm{MA}( \pm \mathrm{SD})$

$\mathrm{Z}$ score ME/MA

MPI

(MPIa-MPIb)/MPIb

$\mathrm{Z}$ score MPI

Ao PSV, cm/s

Ao PSV

Z score Ao PSV

PA PSV, cm/s

PA PSV

Z score PA PSV

Ao valve

Ao valve

$Z$ score Ao valve

PA valve

PA valve

$\mathrm{Z}$ score PA valve

Ao/PA valve

Ao/APA ratio

$\mathrm{Z}$ score Ao/PA

Ductus arteriosus

Ductus arteriosus

Z score Duct art

Aortic arch

Ao arch

Z score Ao arch

Left atrium

Left atrium

Z score LA

Right atrium

Right atrium

Z score RA

Transverse diameter left ventricle

\section{LV tr \\ $\mathrm{Z}$ score LV tr}

Transverse diameter right ventricle

$$
\mathrm{RV} \text { tr }
$$

Z score RV tr

Left ventricular length

LV long

Z score LV long

Right ventricular length

$$
\begin{aligned}
& \mathrm{RV} \text { long } \\
& \mathrm{Z} \text { score RV long }
\end{aligned}
$$

$$
\begin{aligned}
& 0.61( \pm 0.03) \\
& -0.42( \pm 0.39) \\
& 0.60( \pm 0.02) \\
& -0.48( \pm 0.35) \\
& 0.59( \pm 0) \\
& 1.23( \pm 0)
\end{aligned}
$$

$62.13( \pm 7.25)$

$-0.04( \pm 0.28)$

$47.70( \pm 5.23)$

$-0.22( \pm 0.24)$

$3.40( \pm 0.42)$

$-0.17( \pm 0.09)$

$4.30( \pm 0.57)$

$0.42( \pm 0.14)$

$0.79( \pm 0.01)$

$-0.71( \pm 0.01)$

$2.30( \pm 0.28)$

$-0.20( \pm 0.09)$

$2.95( \pm 0.35)$

$0.49( \pm 0.15)$

$7.75( \pm 0.36)$

$0.38( \pm 0.53)$

$7.30( \pm 2.40)$

$<0.001( \pm 2.67)$

$6.15( \pm 0.64)$

$-0.96( \pm 0.13)$

$6.55( \pm 0.21)$

$-0.41( \pm 0.86)$

$1.10( \pm 0.01)$

$-2.04( \pm 0.53)$

$1.19( \pm 0.07)$

$-0.58( \pm 1.21)$

$$
0.73( \pm 0.07)
$$

$0.37( \pm 0.89)$

0.101

0.110

$0.76( \pm 0.12)$

0.162

$0.62( \pm 1.33)$

0.150

$0.52( \pm 0.17)$

0.626

$0.68( \pm 1.00)$

0.608

$103.9( \pm 20.52)$

$0.047^{\mathrm{a}}$

$0.94( \pm 0.65)$

0.198

$83.08( \pm 22.56)$

0.132

$0.63( \pm 0.74)$

0.321

$4.59( \pm 0.57)$

$-0.77( \pm 0.36)$

0.064

$0.006^{\mathrm{a}}$

$5.99( \pm 0.90)$

0.062

$-0.09( \pm 0.56)$

0.367

$0.78( \pm 0.09)$

0.164

$-0.72( \pm 0.47)$

0.219

$3.78( \pm 0.62)$

$0.039^{\mathrm{a}}$

$-0.37( \pm 0.57)$

0.900

$4.40( \pm 0.56)$

$0.028^{\mathrm{a}}$

$0.78( \pm 0.42)$

$0.050^{\mathrm{a}}$

$11.51( \pm 1.66)$

$0.045^{\mathrm{a}}$

$0.22( \pm 1.40)$

$0.046^{\mathrm{a}}$

$12.65( \pm 1.85)$

$0.013^{\mathrm{a}}$

$0.59( \pm 1.29)$

0.888

$10.14( \pm 1.00)$

$0.001^{\mathrm{a}}$

$-0.98( \pm 0.91)$

0.048

$10.25( \pm 1.81)$

$0.002^{\mathrm{a}}$

$-1.07( \pm 1.46)$

$0.041^{\mathrm{a}}$

$1.87( \pm 0.24)$

$0.003^{\mathrm{a}}$

$-0.70( \pm 1.41)$

0.477

$1.78( \pm 0.23)$

$0.016^{\mathrm{a}}$

$-1.09( \pm 1.00)$

$0.045^{\mathrm{a}}$

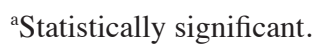


Heart parameters of fetuses from HIV-positive women compared to normal range values. The diastolic function of the two ventricles was altered in fetuses from HIV-positive mothers treated with antiretrovirals. The Z-scores of tricuspid and mitral valve ratio E/A were statistically significant only in the first group: $-0.78( \pm 0.10)$; $\mathrm{P}=0.050$ for the tricuspid valve and $<0.001( \pm 0.23) ; \mathrm{P}=0.047$. $\mathrm{E} / \mathrm{A}$ ratio of the two valves is higher than normal values. In the second group, despite being smaller than normal, E/A ratio has no statistical significance (Table II).

The ratio between the size of the aorta and pulmonary artery is higher in fetuses from HIV-positive mothers under HAART, than in normal fetuses. The Z-scores obtained are statistically significant above the mean value in both gestational age groups: $0.25( \pm 0.48) ; \mathrm{P}=0.027$ in the first group and $0.04( \pm 0.39) ; \mathrm{P}=0.005$ in the second one (Table II). These fetuses have an increased size of the aorta that is only significant between 25 and 31 weeks of gestation $(\mathrm{P}=0.030)$. In addition, we have observed a smaller pulmonary artery in these cases but with no statistical significance

MPI was smaller than normal in the two groups but with statistically significant Z-score only in the first one, between 17 and 24 weeks of gestation [Z-score $1.50( \pm 0)$; $\mathrm{P}=0.001$ ] (Table II).

Regarding the Z scores of both PSV (peak systolic velocity) values of the aorta and pulmonary artery there are statistically significant differences between 25 and 31 weeks of gestation [aortic PSV Z-score $-0.35( \pm 1.00)$; $\mathrm{P}=0.010$ and PSV pulmonary artery Z-score of $0.00( \pm 1.00)$; $\mathrm{P}=0.049$ ]. The PSV of the aorta was higher and that of the pulmonary artery was lower than normal in the second group. In addition, the pulmonary artery PSV value was significantly higher than normal between 17 and 24 weeks of gestation [55.60 ( \pm 2.07$)$; $\mathrm{P}=0.025]$ (Table II).

The difference between the values of ductus arteriosus in fetuses from HIV-positive mothers under HAART and normal fetuses had no statistical significance (Table II).

The right atrium presented no statistically significant alterations. The length of the left ventricle has an increased value compared to normal range in these fetuses, but the result had a statistically significant Z-score only in the first group-fetuses from HIV-positive mothers from 17 to 24 weeks of gestation [-0.03 ( \pm 1.02$) ; \mathrm{P}=0.031]$ (Table II).

Sex-related differences between fetuses. When we tried to determine whether any of these changes were sex-related using ROC curves to assess the correlations based on the values in Table III, we identified some interesting aspects. We statistically analyzed only those fetuses who were delivered by the end of 2019. The cardiac function of 11 fetuses was compared using this parameter.

The ROC curves used to analyze the MoM of these parameters depending on fetal sex showed: Tricuspid valve TrE/TrA (AUC=0.667; 95\% CI: 0.133-1.20; $\mathrm{P}=0.425)$; mitral valve $\mathrm{ME} / \mathrm{MA}(\mathrm{AUC}=0.738 ; 95 \% \mathrm{CI}$ : 0.337-1.139; $\mathrm{P}=0.254$ ); aortic valve ( $\mathrm{AUC}=1.000$; 95\% CI: 1.0-1.0; $\mathrm{P}=0.017)$; pulmonary valve $(\mathrm{AUC}=0.667 ; 95 \% \mathrm{CI}: 0.212-1.121 ; \mathrm{P}=0.425)$; aortic valve to pulmonary valve ratio $(\mathrm{AUC}=0.738 ; 95 \% \mathrm{CI}$ : 0.299-1.177; $\mathrm{P}=0.254)$; ductus arteriosus ( $\mathrm{AUC}=0.905$; 95\% CI: 0.695-1.114; $\mathrm{P}=0.053)$, and aortic arch $(\mathrm{AUC}=0.786$;
95\% CI: 0.411-1.161; $\mathrm{P}=0.411)$ were better predictors in female fetuses.

Using the same curves we found that analysing the MoM for: $\mathrm{MPI}$ (AUC=0762; 95\% CI: 0.419-1.105; $\mathrm{P}=0.210$ ); Ao peak systolic velocity (AUC $=0.881 ; 95 \% \mathrm{CI}$ : 0.637-1.124; $\mathrm{P}=0.068$ ); AP PSV (AUC $=0.810 ; 95 \% \mathrm{CI}: 0.519-1.100 ; \mathrm{P}=0.138)$; right atrium $(\mathrm{AUC}=0.643 ; 95 \% \mathrm{CI}: 0.253-1.032 ; \mathrm{P}=0.494)$; left ventricular transverse diameter $(\mathrm{AUC}=0.714 ; 95 \% \mathrm{CI}$ : 0.244-1.185; $\mathrm{P}=0.305)$; right ventricular transvers diameter (AUC $=0.929 ; 95 \%$ CI: 0.756-1.101; $\mathrm{P}=0.04)$ and left ventricular length (AUC $=0.810$; 95\% CI: 0.524-1.095; $\mathrm{P}=0.138)$ indicated improved predictors in male fetuses.

$\mathrm{Z}$ scores ROC curves confirm that: tricuspid valve TrE/TrA (AUC=0.667; 95\% CI: 0.133-1.20; $\mathrm{P}=0.425$ ); mitral valve $\mathrm{ME} / \mathrm{MA}$ ( $\mathrm{AUC}=0.714 ; 95 \% \mathrm{CI}$ : 0.316-1.112; $\mathrm{P}=0.305$ ); arterial ductus (AUC=0.905; 95\% CI: 0.695-1.114; $\mathrm{P}=0.053$ ); aortic arch (AUC=0.762; 95\% CI: 0.354-1.170; $\mathrm{P}=0.210)$; aortic valve $(\mathrm{AUC}=1.000 ; 95 \% \mathrm{CI}: 1.0-1.0 ; \mathrm{P}=0.017)$ and pulmonary valve $(\mathrm{AUC}=0.643 ; 95 \% \mathrm{CI}: 0.160-1.126 ; \mathrm{P}=0.494)$ indicated improved predictors in female fetuses.

$\mathrm{Z}$ scores ROC curves show us that: MPI (AUC $=0.762$; 95\% CI: 0.419-1.105; $\mathrm{P}=0.210$ ); AO PSV (AUC=0.905; 95\% CI: 0.695-1.114; $\mathrm{P}=0.053$ ); AP PSV (AUC $=0.833 ; 95 \%$ CI: $0.519-1.115 ; \mathrm{P}=0.111)$; left ventricular transverse diameter (AUC $=0.714 ; 95 \%$ CI: 0.244-1.185; $\mathrm{P}=0.305)$; right ventricular transverse diameter (AUC $=0.905 ; 95 \%$ CI: 0.695-1.114; $\mathrm{P}=0.053$ ) and left ventricular length $(\mathrm{AUC}=0.667 ; 95 \% \mathrm{CI}$ : 0.269-1.065; $\mathrm{P}=0.425)$ were improved predictors in male fetuses.

\section{Discussion}

The significant positive impact of ART in HIV-positive mothers is mildly shadowed by concerns about side effects, especially fetal side effects. HIV-positive pregnant women may be tempted to discontinue treatment for this disease due to worries about fetal health. Few studies are aimed at assessing ART side effects and establishing management protocols to reduce their negative impact on HEU children. The prevalence of HEU children is on the increase due to the success of therapy in prolonging lifespan and reducing vertical transmission. Thus, it becomes very important to detect the possible side effects and to manage them in order to improve the quality of life of these children and ensure the mother's adhesion to treatment $(3,5)$.

According to the data from literature there is a decrease in left ventricular dimensions and function $(17,18)$. However, the results showed an increase in left ventricular longitudinal diameter, but a decrease of diastolic function reflected by the $\operatorname{TrE} / \operatorname{TrA}$ ratio that was smaller than normal range in fetuses from HIV-positive mothers between 25 and 31 weeks of gestation, but without any statistical significance. The smaller ratios reflect a reduced ventricular compliance suggestive for a diastolic dysfunction due to myocardial hypertrophy. In the first group both ventricles had an increased E/A ratio, both having statistically significant $\mathrm{Z}$ scores. If initially the ventricular function was normal between 17 and 24 weeks of gestation in these fetuses afterwards, we observed an alteration in both ventricular function between 25 and 31 weeks.

De la Calle et al did not find any significant alterations in the cardiac structure or function of these fetuses, whereas 
Table II. Fetal cardiac parameters-differences between fetuses from HIV-positive mothers under HAART and normal values.

\begin{tabular}{|c|c|c|c|c|c|c|}
\hline \multirow[b]{2}{*}{ Parameter } & \multicolumn{2}{|c|}{ 17-24 weeks of gestation } & \multirow[b]{2}{*}{ P-value } & \multicolumn{2}{|c|}{ 25-31 weeks of gestation } & \multirow[b]{2}{*}{ t-test/P-value } \\
\hline & Control group & Student's t-test & & $\begin{array}{l}\text { HIV fetuses } \\
\text { Control group }\end{array}$ & $\begin{array}{l}\text { Student's } \\
\text { values }\end{array}$ & \\
\hline $\operatorname{TrE}( \pm \mathrm{SD})$ & $36.05( \pm 1.92)$ & $29.0( \pm 4.0)$ & $0.017^{\mathrm{a}}$ & $41.32( \pm 3.23)$ & $35.0( \pm 6.0)$ & $0.001^{\mathrm{a}}$ \\
\hline $\operatorname{TrA}( \pm \mathrm{SD})$ & $58.99( \pm 0.51)$ & $45.0( \pm 6.0)$ & $0.001^{\mathrm{a}}$ & $57.02( \pm 6.16)$ & $49.0( \pm 8.0)$ & $0.005^{\mathrm{a}}$ \\
\hline $\operatorname{TrE} / \operatorname{Tr} \mathrm{A}( \pm \mathrm{SD})$ & $0.61( \pm 0.03)$ & $0.64( \pm 0.07)$ & $0.044^{\mathrm{a}}$ & $0.73( \pm 0.07)$ & $0.70( \pm 0.08)$ & 0.303 \\
\hline $\mathrm{Z}$ score $\operatorname{TrE} / \mathrm{Tr} \mathrm{A}$ & $-0.42( \pm 0.39)$ & $-0.78( \pm 0.10)$ & $0.050^{\mathrm{a}}$ & $0.37( \pm 0.89)$ & $0.00( \pm 0.11)$ & 0.293 \\
\hline $\mathrm{ME}( \pm \mathrm{SD})$ & $34.31( \pm 0.15)$ & $26.0( \pm 4.0)$ & $0.001^{\mathrm{a}}$ & $43.97( \pm 5.14)$ & $31.0( \pm 5.0)$ & $0.001^{\mathrm{a}}$ \\
\hline $\mathrm{MA}( \pm \mathrm{SD})$ & $57.33( \pm 2.58)$ & $41.0( \pm 6.0)$ & $0.001^{\mathrm{a}}$ & $59.06( \pm 8.66)$ & $45.0( \pm 7.0)$ & $0.002^{\mathrm{a}}$ \\
\hline $\mathrm{ME} / \mathrm{MA}( \pm \mathrm{SD})$ & $0.60( \pm 0.02)$ & $0.63( \pm 0.07)$ & $0.050^{\mathrm{a}}$ & $0.76( \pm 0.12)$ & $0.70( \pm 0.09)$ & 0.284 \\
\hline $\mathrm{Z}$ score $\mathrm{ME} / \mathrm{MA}$ & $-0.48( \pm 0.35)$ & $0.0( \pm 0.23)$ & $0.047^{\mathrm{a}}$ & $0.62( \pm 1.33)$ & $0.0( \pm 0.10)$ & 0.284 \\
\hline MPI $( \pm S D)$ & $0.59( \pm 0.001)$ & $0.49( \pm 0.14)$ & $0.001^{\mathrm{a}}$ & $0.52( \pm 0.17)$ & $0.35( \pm 0.22)$ & $0.023^{\mathrm{a}}$ \\
\hline Z score MPI & $1.23( \pm 0)$ & $1.50( \pm 0)$ & $0.001^{\mathrm{a}}$ & $0.68( \pm 1.01)$ & $0.00( \pm 0.58)$ & 0.137 \\
\hline AO valve $( \pm \mathrm{SD})$ & $3.40( \pm 0.42)$ & $3.43( \pm 0.60)$ & 0.956 & $4.59( \pm 0.56)$ & $5.27( \pm 0.53)$ & $0.030^{\mathrm{a}}$ \\
\hline $\mathrm{Ao} / \mathrm{PA}( \pm \mathrm{SD})$ & $0.79( \pm 0.01)$ & $0.92( \pm 0.01)$ & $0.001^{\mathrm{a}}$ & $0.78( \pm 0.09)$ & $0.91( \pm 0.01)$ & $0.002^{\mathrm{a}}$ \\
\hline $\mathrm{Z}$ score $\mathrm{Ao} / \mathrm{PA}$ & $-0.71( \pm 0.01)$ & $0.25( \pm 0.48)$ & $0.027^{\mathrm{a}}$ & $-0.72( \pm 0.47)$ & $0.04( \pm 0.39)$ & $0.005^{\mathrm{a}}$ \\
\hline Ao PSV ( $( \pm \mathrm{SD})$ & $62.13( \pm 7.25)$ & $64.60( \pm 2.07)$ & 0.465 & $103.9( \pm 20.52)$ & $106.3( \pm 2.87)$ & 0.858 \\
\hline Z score Ao PSV & $-0.04( \pm 0.28)$ & $-0.19( \pm 1.0)$ & 0.847 & $0.94( \pm 0.65)$ & $-0.35( \pm 1.00)$ & $0.010^{\mathrm{a}}$ \\
\hline AP PSV (土SD) & $47.70( \pm 5.23)$ & $55.60( \pm 2.07)$ & $0.025^{\mathrm{a}}$ & $83.08( \pm 22.56)$ & $62.85( \pm 2.41)$ & $0.035^{\mathrm{a}}$ \\
\hline Z score PA PSV & $-0.22( \pm 0.24)$ & $-0.19( \pm 1.0)$ & 0.974 & $0.63( \pm 0.74)$ & $0.00( \pm 1.00)$ & $0.049^{\mathrm{a}}$ \\
\hline Duct. Art. $( \pm \mathrm{SD})$ & $2.30( \pm 0.28)$ & $2.45( \pm 0.35)$ & 0.610 & $3.38( \pm 0.62)$ & $3.65( \pm 0.39)$ & 0.329 \\
\hline Z score Duct. Art. & $-0.20( \pm 0.09)$ & $-0.02( \pm 1.00)$ & 0.778 & $-0.37( \pm 0.57)$ & $0.01( \pm 1.01)$ & 0.374 \\
\hline Right atrium ( \pm SD) & $7.30( \pm 2.40)$ & $7.58( \pm 2.44)$ & 0.832 & $12.65( \pm 1.85)$ & $11.60( \pm 1.08)$ & 0.211 \\
\hline Z score Right atrium & $0.00( \pm 2.67)$ & $-0.02( \pm 1.00)$ & 0.987 & $0.59( \pm 1.29)$ & $0.01( \pm 1.00)$ & 0.343 \\
\hline Left ventricle long $( \pm \mathrm{SD})$ & $1.10( \pm 0.01)$ & $1.40( \pm 0.23)$ & 0.118 & $1.87( \pm 0.24)$ & $2.11( \pm 0.21)$ & $0.050^{\mathrm{a}}$ \\
\hline $\mathrm{Z}$ score Left ventricle long & $-2.04( \pm 0.53)$ & $-0.03( \pm 1.02)$ & $0.031^{\mathrm{a}}$ & $-0.70( \pm 1.41)$ & $-0.01( \pm 0.99)$ & 0.295 \\
\hline
\end{tabular}

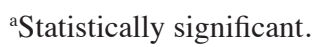

Table III. Fetal cardiac evaluation of HIV-positive pregnant women under HAART therapy depending on the sex of the fetus.

\begin{tabular}{|c|c|c|c|}
\hline \multirow[b]{2}{*}{ Parameter } & \multicolumn{2}{|c|}{ Fetal sex } & \multirow[b]{2}{*}{ One-way ANOVA test P-value } \\
\hline & Masculine $(n=4)$ & Feminine $(n=7)$ & \\
\hline $\mathrm{Z}$ score $\operatorname{TrE} / \operatorname{Tr} \mathrm{A}$ & $-0.35 \pm 1.45$ & $0.27 \pm 0.66$ & 0.353 \\
\hline $\mathrm{Z}$ score $\mathrm{ME} / \mathrm{MA}$ & $-0.61 \pm 1.59$ & $0.62 \pm 1.20$ & 0.181 \\
\hline Z score MPI & $1.38 \pm 1.00$ & $0.61 \pm 0.91$ & 0.269 \\
\hline Z score AO PSV & $1.13 \pm 0.88$ & $0.53 \pm 0.48$ & 0.174 \\
\hline Z score AP PSV & $0.88 \pm 1.04$ & $0.27 \pm 0.41$ & 0.197 \\
\hline $\mathrm{Z}$ score $\mathrm{AO}$ valve & $-1.24 \pm 0.76$ & $-0.52 \pm 0.22$ & $0.039^{\mathrm{a}}$ \\
\hline $\mathrm{Z}$ score AP valve & $-0.22 \pm 0.80$ & $0.07 \pm 0.35$ & 0.413 \\
\hline $\mathrm{Z}$ score $\mathrm{AO} / \mathrm{AP}$ & $-1.08 \pm 0.64$ & $-0.64 \pm 0.31$ & 0.155 \\
\hline Z score Arterial ductus & $-0.68 \pm 0.50$ & $-0.13 \pm 0.36$ & 0.063 \\
\hline $\mathrm{Z}$ score $\mathrm{AO}$ arch & $0.27 \pm 0.62$ & $0.81 \pm 0.35$ & 0.091 \\
\hline Z score Left Atrium & $0.39 \pm 2.05$ & $-0.18 \pm 1.01$ & 0.544 \\
\hline Z score Right Atrium & $0.04 \pm 1.44$ & $0.72 \pm 1.41$ & 0.463 \\
\hline Z score Left Ventricle transverse diameter & $-1.18 \pm 0.64$ & $-0.45 \pm 0.90$ & 0.149 \\
\hline Z score Right Ventricle transverse diameter & $-0.66 \pm 1.07$ & $-1.45 \pm 1.21$ & $0.018^{\mathrm{a}}$ \\
\hline Z score Right Ventricle length & $-0.81 \pm 1.26$ & $-1.24 \pm 0.87$ & 0.516 \\
\hline
\end{tabular}


results of the present study showed many statistically significant differences in both gestational age groups (19). In the first group many functional parameters of the fetal heart had statistically significant alterations: Both mitral and tricuspid valves had altered E/A ratio and also altered MPI. In the second group both aortic and pulmonary PSV differ from normal range.

In the present study, we detected sex-related differences in fetal cardiac function. We identified a prolonged tricuspid $\operatorname{TrE} / \operatorname{Tr} \mathrm{A}$ ratio that was better correlated with female sex, but the difference was not statistically significant when compared to normal values. This result was sustained by other studies from literature (20). The fetal sex-related cardiac alterations found in the current study seem to differ from previous data found in literature $(18,19)$.

In the present study, statistically significant changes in the great vessel diameter, arch, and ductus arteriosus in female fetuses and changes in cardiac chamber size in male fetuses. MPI evaluation showed no statistically significant alterations, only greater values than normal. The only two findings with better fetal-sex correlations and also statistically significant were a smaller aortic diameter in female fetuses and a reduced right ventricular transverse diameter in male fetuses.

None of the studies from the literature describe alterations in fetal cardiac chambers diameters or the diameters of the great vessels. Children included in the present and other studies need postpartum cardiac assessment to confirm these aspects. There are few studies which observed a normalization of a previous ultrasound considered modified fetal aorta in postpartum (20). This factor needs further investigation.

It has become increasingly difficult for the obstetrician to correctly diagnose and to properly advise these women if they are not aware of these alterations. This is one of the reasons for properly determining the impact of antiretroviral drugs on fetal cardiac structure and function $(20,21)$.

Despite these alterations in fetal heart structure, its global function reflected by MPI seems to be preserved in time, as the gestational age advances. The MPI index, although it is smaller, has no statistically significant value in the second group, but we still need to monitor fetal ventricular diastolic dysfunction.

To the best of our knowledge, this is the first study conducted in Romania that evaluates these aspects.

Despite the small sample size (only 14 fetuses), with only 17 evaluations of the fetal heart, the impact of ART on cardiac structure and function seems to be significant only in regard to some of the structural and functional parameters, and also sex-related.

These children from HIV-positive mothers on HAART need further cardiac assessment to confirm the persistence of these cardiac changes later in childhood and to establish management protocols aimed at improving their health.

Accurate and complete patient information about the risks and benefits of antiretroviral treatment and management strategies to improve fetal outcomes may also ensure better compliance of the mothers with the treatment.

These children therefore need to be followed up after birth in order to correlate the intrapartum cardiac alterations with those found in postpartum. This is one of our future goals. Another one is to try to correlate the nuchal translucency thickness with changes in the aortic diameter in these HEU children of
HIV-positive mothers because there are studies in the literature that suggest this association. If these assumptions are confirmed, it may mean a reduction in the accuracy of first-trimester fetal screening for aneuploidy in this group of women (21).

\section{Acknowledgements}

Not applicable.

\section{Funding}

No funding was received.

\section{Availability of data and materials}

The datasets used and/or analyzed during this study are available from the corresponding author on reasonable request.

\section{Authors' contributions}

AU, DN, DRM were involved in the conception of the study and data interpretation and wrote the manuscript. AMT, AL, DN contributed to data collection and performed the statistical analysis. DN and MO revised the manuscript for important intellectual content. All authors read and approved the final version of the manuscript.

\section{Ethics approval and consent to participate}

Approval was obtained from the Ethics Committee of the Iasi 'Gr. T. Popa' University of Medicine and written consent was obtained from all the participants (no. 24411/11.05.2018).

\section{Patient consent for publication}

Not applicable.

\section{Competing interests}

The authors declare that they have no competing interests.

\section{References}

1. Dorobăţ CM, Haliciu AM and Bejan C: Interdisciplinary correlations regarding the clinical and paraclinical evaluations in HIV-positive pregnant women. Rev Med Chir Soc Med Nat Iasi 3: 749-752, 2014.

2. Sharp PM and Hahn BH: Origins of HIV and the AIDS Pandemic. Cold Spring Harb Perspect Med 1: a006841, 2011.

3. Smith JH and Whiteside A: The history of AIDS exceptionalism. J Int AIDS Soc 13: 47, 2010.

4. Wainberg MA and Jeang KT: 25 years of HIV-1 research-progress and perspectives. BMC Med 6: 31, 2008.

5. Greene WC: A history of AIDS: Looking back to see ahead. Eur J Immunol 37 (Suppl 1): S94-S102, 2007.

6. Pau AK and George JM: Antiretroviral therapy: Current drugs. Infect Dis Clin North Am 3: 371-402, 2014.

7. Fanales-Belasio E, Raimondo M, Suligoi B and Buttò S: HIV virology and pathogenetic mechanisms of infection: A brief overview. Ann Ist super Sanità 1: 5-14, 2010.

8. Lu DY, Wu HY, Yarla NS, Xu B, Ding J and Lu TR: HAART in HIV/AIDS treatments: Future trends. Infect Disord Drug Targets 1: 15-22, 2018.

9. Barbaro G: Cardiovascular manifestations of HIV infection. J R Soc Med 8: 384-90, 2001. 
10. Prendergast BD: HIV and cardiovascular medicine. Heart 7 : 793-800, 2003

11. Hajjar LA, Calderaro D, Yu PC, Giuliano I, Lima EM, Barbaro G and Caramelli B: Cardiovascular manifestations in patients infected with the human immunodeficiency virus. Arq Bras Cardiol 5: 363-377, 2005 (In Portuguese).

12. Thienemann F, Sliwa K and Rockstroh JK: HIV and the heart: The impact of antiretroviraltherapy: A global perspective. Eur Heart J 46: 3538-3546, 2013.

13. Chandwani A and Shuter J: Lopinavir/ritonavir in the treatment of HIV-1 infection: A review. Ther Clin Risk Manag 5: 1023-1033, 2008.

14. Portsmouth SD and Scott CJ: The renaissance of fixed dose combinations: Combivir. Ther Clin Risk Manag 4: 579-583, 2007.

15. Kline-Fath BM, Bahado-Singh R and Bulas DI: Advanced assessment of fetal cardiac function. In: Fundamental and Advanced Fetal Imaging: Ultrasound and MRI. 1st edition. Ed. Wolters Kluwer Health, pp114-164, 2015.

16. Abuhamad A and Chaoui R: Pulsed Doppler in fetal echocardiography. In: A Practical Guide to Fetal Echocardiography-Norma and Abnormal Hearts. 3rd edition. Ed. Wolters Kluwer Health, pp160-117, 2010 .
17. Abuhamad A and Chaoui R: Fetal cardiac fonction. In: A Practical Guide to Fetal Echocardiography-Normal and Abnormal Hearts. 3rd edition. Ed. Wolters Kluwer Health, pp178-199, 2010.

18. Hornberger LK, Lipshultz SE, Easley KA, Colan SD, Schwartz M, Kaplan S, Starc TJ, Ayres NA, Lai WW, Moodie DS, et al: Cardiac structure and function in fetuses of mothers infected with HIV: The prospective PCHIV multicenter study. Am Heart J 140: 575-584, 2000

19. De la Calle M, Rodriguez R, Deiros L and Bartha L: Fetal cardiac biometry and function in HIV-infected pregnant women exposed to HAART therapy. Prenat Diagn 5: 453-455, 2015.

20. Kim HS, Hong YM, Sohn S and Choi JY: Perinatal changes in size of the fetal great arteries. Korean Circ J 10: 414-417, 2009.

21. Achiron R, Zimand S, Hegesh J, Lipitz S, Zalel Y and Rotstein Z: Fetal aortic arch measurements between 14 and 38 weeks' of gestation: In-utero ultrasonographic study. Ultrasound Obst Gynecol 15: 226-230, 2000.

This work is licensed under a Creative Commons Attribution-NonCommercial-NoDerivatives 4.0 International (CC BY-NC-ND 4.0) License. 